Науковий вісник Аьвівського національного університету ветеринарної медицини та біотехнодогій імені С.3. Гжицького

\author{
Scientific Messenger of Lviv National University \\ of Veterinary Medicine and Biotechnologies
}

UDC 636.598.082.22

\title{
Correlation variability between live weight and weight of the incubation egg and body measurements of Obroshynska gray and Obroshynska white natural groups geese
}

\author{
V.S. Zaplatynsky, E.I. Fedorovych \\ Institute of animal biology NAAS, Lviv, Ukraine \\ Article info \\ Received 02.02.2018 \\ Received in revised form \\ 28.02 .2018 \\ Accepted 06.03.2018 \\ Zaplatynsky, V.S., \& Fedorovych, E.I. (2018). Correlation variability between live weight and \\ weight of the incubation egg and body measurements of Obroshynska gray and Obroshynska white \\ natural groups geese. Scientific Messenger of Lviv National University of Veterinary Medicine and \\ Biotechnologies. 20(84), 93-97. doi: 10.15421/nvlvet8417
}

Institute of animal biology NAAS, Vasyl Stus Str., 38, Lviv, 79034,

Ukraine.

Tel.: $+38-096-572-12-25$

E-mail:vova25502012@ukr.net
This article shows data analysis of the correlation between the live weight of Obroshynska gray and Obroshynska white natural groups geese and the weight of the incubation egg, beside this the age repeatability of the live weight of the poultry has been investigated and the correlation variability of the aforementioned indicators and body measurements of the females and males of geese breeds have been analyzed. It was established that the most significant and highly reliable correlation bundles were between live weight and the weight of the incubation egg were detected in one day aged geese. In another researched age periods, these connections were sharply weakened and at 60-day aged geese reached the minimum values and were inconceivable. With the increase of the interval between the comparable age periods and the coefficients of repeatability of live weight were declined. In Obroshinsky gray natural group geese females - the coefficients of repeatability of live weight were depending on age and they ranged from 0.01 to 0.55 , in males - from 0.01 to 0.57, and in the bird of the Obroshinsky white natural group geese were from 0,03 to 0.53 , and from 0.02 to 0.65 respectively. In 30 to 60 days of aged geese of both sexes of both natural groups the coefficients of repetition of live weight were the highest and reached more than $50 \%$ at their high level. This indicates that live weight of geese selection can be carried out already at 30-day aged geese. The highest coefficients of the correlation in the birds of both geese natural groups were observed in all studied age periods between the live weight and the width of the pelvis, the length of the trunk, the length of the keel and the chest covering of the shoulder blades: in females they were within the range of 0.58-0.96, and in males - in the range 0.50-0.96 at $P<0.001$ in all cases. However, it should be noted that the correlation of live weight, the length of the body and the length of the keel in both sexes geese from Obroshinsky gray natural group were more significant than in geese from Obroshinsky white natural group, but the correlation bonds between the living weight with the width of the pelvis and the chest covering of the shoulder blades on the contrary, were weaker. The weakest correlation were detected between the live weight and the length of the mold, leg and thigh in the poultry of both sexes of both groups in the 30-60 days aged geese.

Key words: geese, Obroshinsky white natural group, Obroshinsky gray natural group, weight of incubation egg, live weight, body measurements, coefficient of repeatability, correlation coefficient.

\section{Співвідносна мінливість живої маси та маси інкубаційного яйця і промірів тіла гусей оброшинської сірої та оброшинської білої породних груп}

\author{
В.С. Заплатинський, Є.І. Федорович
}

Інститут біологї тварин НААН, м. Львів, Україна

Наведено дані щуодо зв'язку живої маси гусей оброшинської сірої та оброшинської білої породних груп з масою інкубаційного яйця, досліджено вікову повторюваність живої маси птиці, проведено аналіз співвідносної мінливості вищеназваного показника та промірів тіла самок і самців гусей досліджуваних порід. Встановлено, щзо найбільш суттєві та високодостовірні зв 'язки маси інкубаційного яйчя були виявлені з живою масою гусенят у добовому віці. У подальщі вікові періоди ичі зв 'язки різко послаблювалися 
і у 60-добовому віці сягали мінімальних значень та були невірогідними. Зі збільщенням інтервалу між порівнюваними віковими періодами коефічієнти повторюваності живої маси знижувалися. У самок гусей оброшинської сірої породної групи, залежно від вікового періоду, вони коливалися від 0,01 до 0,55, у самців - від 0,01 до 0,57, а у птиці оброшинської білої породної групи - відповідно від 0,03 до 0,53 та від 0,02 до 0,65. 3 30- до 60-добового віку коефічієнти повторюваності живої маси у гусей обох статей обох породних груп були найвищими і сягали понад $50 \%$ за високодостовірного їх рівня. Це вказує на те, щзо добір гусей за живою масою можна проводити уже у 30-добовому віці. Найвищі коефіцієнти кореляції у птиці обох породних груп майже у всі досліджувані вікові періоди спостерігалися між живою масою та шириною таза, довжиною тулуба, довжиною кіля і обхватом грудей за лопатками: у самок вони були в межах 0,58-0,96, а у самців - в межах 0,50-0,96 при P < 0,001 в усіх випадках. Проте варто зазначити, шзо зв 'язки живої маси з довжиною тулуба та з довжиною кіл як у самок, так і у самиів гусей оброшинської сірої породної групи були більш суттєвими, ніж у їхніх ровесників оброчинської білої породної групи, тимчасом як зв'язки живої маси з иириною таза та обхватом грудей за лопатками, навпаки, були слабшими. Найслабші зв'язки були виявлені між живою масою та довжиною плесни, гомілки і стегна у птиці обох статей обох породних груп у віковий період 30-60 діб.

Ключові слова: гуси, оброшинська біла породна група, оброшинська сіра породна група, маса інкубаційного яйия, жива маса, проміри тіла, коефіцієнт повторюваності, коефіцієнт кореляиї.

\section{Ветуп}

Організм птиці розвивається під дією численних факторів, які по-різному визначають розвиток ознак (Khomyk, 2009; Khvostyk, 2012; Fialovych and Kyryliv, 2016; Sobolev et al., 2017). Встановлення зв'язків продуктивних ознак 3 конституційними особливостями організму птиці викликають значну зацікавленість при ранньому визначенні продуктивності (Pustova, 2004; Zaplatynsky, 2017). Дослідження різних авторів відображають відмінність зв'язків одних і тих же ознак у птиці певного виду залежно від породи, кросу, лінії, статі, віку, впливу умов вирощування та зовнішнього середовища. Знання цих зв'язків дозволяє поліпшити ефективність відбору гусей на плем'я в молодому віці, а також вести селекцію за бажаною ознакою (Grishina, 2016; Petriv et al., 2016). 3 огляду на зазначене, для ефективного добору гусей та раннього прогнозування їхньої живої маси доцільним вбачається дослідити зв'язки маси інкубаційного яйця з живою масою молодняку гусей, а також їх живої маси з промірами тіла та вікову повторюваність живої маси.

\section{Матеріал і методи досліджень}

Дослідження проведені на гусях оброшинської сірої та новостворюваної оброшинської білої породних груп в умовах ДП «ДГ Миклашівське» Інституту сільського господарства Карпатського регіону НААН. У вибірку включено всього 421 гусеня. Для визначення маси яєць та живої маси гусенят використовували ваги SF-400 з точністю до 0,01 г. Проміри тіла дослідної птиці брали за допомогою мірної стрічки та кронциркуля у віці 30, 60, 90, 120, 150 та 180 діб за загальноприйнятими методиками (Lakin, 1990; Petriv et al., 2017; Zaplatinsky and Fedorovich, 2017).

Співвідносну мінливість маси інкубаційних яєць та живої маси, живої маси та промірів тіла самок i самців гусей досліджуваних порід, а також коефіцієнти вікової повторюваності живої маси визначали згідно 3 загальноприйнятими методами за допомогою програми Microsoft Excel (Kyryliv et al., 2002). Результати середніх значень вважали статистично вірогідними при $\mathrm{P}<0,05(*), \mathrm{P}<0,01(* *), \mathrm{P}<0,001$ (***).

\section{Результати та їх обговорення}

Встановлено, що коефіцієнти кореляції між масою інкубаційного яйця та живою масою гусенят певним чином залежали від їхньої статі і в молодняку обох породних груп набували додатного значення (табл. 1). Однак варто відмітити, що міжпородна та міжстатева різниця за вищенаведеними зв'язками була незначною.

\section{Таблиця 1}

Зв’язок маси інкубаційного яйця з живою масою гусей у різні вікові періоди

\begin{tabular}{llcccc}
\hline \multirow{2}{*}{ Поєднання показників } & \multicolumn{2}{c}{ Оброшинська сіра породна група } & \multicolumn{2}{c}{ Оброшинська біла породна група } \\
\cline { 2 - 5 } & самки $(\mathrm{n}=111)$ & самці $(\mathrm{n}=75)$ & самки $(\mathrm{n}=128)$ & самці $(\mathrm{n}=107)$ \\
\hline \multirow{2}{*}{ Маса } & жива маса добового молодняку & $0,89 \pm 0,044^{* * *}$ & $0,85 \pm 0,033^{* * *}$ & $0,91 \pm 0,037^{* * *}$ & $0,79 \pm 0,060^{* * *}$ \\
\multirow{2}{*}{ яйця } & жива маса молодняку у віці 30 діб & $0,19 \pm 0,094^{*}$ & $0,27 \pm 0,107^{* *}$ & $0,29 \pm 0,085^{* * *}$ & $0,30 \pm 0,093^{* *}$ \\
& жива маса молодняку у віці 60 діб & $0,11 \pm 0,95$ & $0,20 \pm 0,111$ & $0,17 \pm 0,088$ & $0,09 \pm 0,097$ \\
\hline
\end{tabular}

Найбільш суттєві та високодостовірні зв'язки маси інкубаційного яйця були виявлені 3 живою масою гусенят у добовому віці. У подальші вікові періоди ці зв'язки різко послаблювалися і у 60-добовому віці сягали мінімальних значень та були невірогідними.

3 метою можливості прогнозування живої маси гусей на більш ранніх етапах їх вирощування нами було визначено коефіцієнти вікової повторюваності цього показника (табл. 2). Значної міжстатевої та міжпородної різниці за названим коефіцієнтом не спостерігалося, однак варто відмітити, що із збільшенням інтерва- лу між порівнюваними віковими періодами коефіцієнти повторюваності живої маси знижувалися. У самок гусей оброшинської сірої породної групи, залежно від вікового періоду, вони коливалися від 0,01 до 0,55, у самців - від 0,01 до 0,57, а у птиці оброшинської білої породної групи - відповідно від 0,03 до 0,53 , та від 0,02 до 0,65. Аналіз даних свідчить, що починаючи із 30- до 60-добового віку коефіцієнти повторюваності живої маси у гусей обох статей обох породних груп були найвищими і сягали понад 50\% за високодостовірного їх рівня. 
Таблиця 2

Вікова повторюваність живої маси гусей оброшинської селекції

\begin{tabular}{|c|c|c|c|c|}
\hline \multirow{2}{*}{$\begin{array}{c}\text { Зв’язок живої маси у } \\
\text { віці, діб }\end{array}$} & \multicolumn{2}{|c|}{ Оброшинська сіра породна група } & \multicolumn{2}{|c|}{ Оброшинська біла породна група } \\
\hline & самки $(\mathrm{n}=111)$ & самці $(\mathrm{n}=75)$ & самки $(\mathrm{n}=128)$ & самці $(\mathrm{n}=107)$ \\
\hline $1-30$ & $0,35 \pm 0,090 * * *$ & $0,21 \pm 0,110$ & $0,34 \pm 0,084 * * *$ & $0,39 \pm 0,090 * * *$ \\
\hline $1-60$ & $0,23 \pm 0,093 * *$ & $0,30 \pm 0,105^{* *}$ & $0,22 \pm 0,087^{*}$ & $0,19 \pm 0,096^{*}$ \\
\hline $1-90$ & $0,29 \pm 0,092 * *$ & $0,18 \pm 0,112$ & $0,25 \pm 0,086^{* *}$ & $0,27 \pm 0,094 * *$ \\
\hline $1-120$ & $0,16 \pm 0,095$ & $0,15 \pm 0,113$ & $0,07 \pm 0,089$ & $0,19 \pm 0,096^{*}$ \\
\hline $1-150$ & $0,01 \pm 0,096$ & $0,07 \pm 0,115$ & $0,08 \pm 0,089$ & $0,12 \pm 0,097$ \\
\hline $1-180$ & $0,04 \pm 0,096$ & $0,03 \pm 0,115$ & $0,09 \pm 0,089$ & $0,03 \pm 0,098$ \\
\hline $30-60$ & $0,55 \pm 0,080^{* * *}$ & $0,57 \pm 0,078 * * *$ & $0,53 \pm 0,080 * * *$ & $0,65 \pm 0,074 * * *$ \\
\hline 30-90 & $0,24 \pm 0,093 * *$ & $0,39 \pm 0,098^{* * *}$ & $0,29 \pm 0,085^{* * *}$ & $0,47 \pm 0,086^{* * *}$ \\
\hline $30-120$ & $0,06 \pm 0,096$ & $0,01 \pm 0,115$ & $0,14 \pm 0,088$ & $0,07 \pm 0,097 * * *$ \\
\hline $30-150$ & $0,14 \pm 0,095$ & $0,06 \pm 0,115$ & $0,07 \pm 0,089$ & $0,15 \pm 0,096$ \\
\hline $30-180$ & $0,01 \pm 0,096$ & $0,26 \pm 0,108^{*}$ & $0,04 \pm 0,089$ & $0,06 \pm 0,097$ \\
\hline 60-90 & $0,23 \pm 0,093^{*}$ & $0,35 \pm 0,101 * * *$ & $0,42 \pm 0,081 * * *$ & $0,40 \pm 0,089^{* * *}$ \\
\hline $60-120$ & $0,10 \pm 0,095$ & $0,28 \pm 0,107 * *$ & $0,11 \pm 0,089$ & $0,04 \pm 0,098$ \\
\hline $60-150$ & $0,09 \pm 0,095$ & $0,19 \pm 0,111$ & $0,06 \pm 0,089$ & $0,15 \pm 0,097$ \\
\hline $60-180$ & $0,07 \pm 0,096$ & $0,24 \pm 0,109 *$ & $0,13 \pm 0,088$ & $0,02 \pm 0,098$ \\
\hline $90-120$ & $0,15 \pm 0,095$ & $0,27 \pm 0,107 *$ & $0,16 \pm 0,088$ & $0,13 \pm 0,097$ \\
\hline $90-150$ & $0,07 \pm 0,096$ & $0,04 \pm 0,115$ & $0,03 \pm 0,089$ & $0,07 \pm 0,097$ \\
\hline $90-180$ & $0,10 \pm 0,095$ & $0,27 \pm 0,107 *$ & $0,15 \pm 0,088$ & $0,03 \pm 0,098$ \\
\hline $120-150$ & $0,32 \pm 0,091^{* *}$ & $0,18 \pm 0,112$ & $0,21 \pm 0,087 *$ & $0,05 \pm 0,097$ \\
\hline $120-180$ & $0,10 \pm 0,095$ & $0,11 \pm 0,114$ & $0,03 \pm 0,089$ & $0,12 \pm 0,097$ \\
\hline $150-180$ & $0,19 \pm 0,094$ & $0,27 \pm 0,107 *$ & $0,19 \pm 0,087 *$ & $0,14 \pm 0,97$ \\
\hline
\end{tabular}

Таблиця 3

Зв'язок живої маси з промірами тіла самок гусей

\begin{tabular}{|c|c|c|c|c|c|c|c|}
\hline \multirow{3}{*}{\multicolumn{2}{|c|}{ Поєднання показників }} & \multicolumn{6}{|c|}{ Оброшинська сіра породна група $(\mathrm{n}=111)$} \\
\hline & & \multicolumn{6}{|c|}{ Віковий період } \\
\hline & & 30 діб & 60 діб & 90 діб & 120 діб & 150 & 180 \\
\hline \multirow{8}{*}{$\begin{array}{l}\text { Жива } \\
\text { маса }\end{array}$} & довжина тулуба & $0,81 \pm 0,057 * * *$ & $0,72 \pm 0,045 * * *$ & $0,61 \pm 0,076^{* * *}$ & $0,72 \pm 0,066 * * *$ & $0,68 \pm 0,070 * * *$ & $0,70 \pm 0,068 * * *$ \\
\hline & довжина кіля & $0,58 \pm 0,078 * * *$ & $0,73 \pm 0,044 * * *$ & $0,62 \pm 0,075 * * *$ & $0,70 \pm 0,068 * * *$ & $0,78 \pm 0,057 * * *$ & $0,71 \pm 0,067 * * *$ \\
\hline & довжина плесни & $0,35 \pm 0,090 * * *$ & $0,32 \pm 0,085 * * *$ & $0,55 \pm 0,080 * * *$ & $0,63 \pm 0,074 * * *$ & $0,53 \pm 0,081 * * *$ & $0,60 \pm 0,076^{* * *}$ \\
\hline & довжина гомілки & $0,33 \pm 0,085 * * *$ & $0,42 \pm 0,078 * * *$ & $0,54 \pm 0,081 * * *$ & $0,53 \pm 0,081 * * *$ & $0,60 \pm 0,077 * * *$ & $0,54 \pm 0,081 * * *$ \\
\hline & довжина стегна & $0,44 \pm 0,086^{* * *}$ & $0,55 \pm 0,066^{* * *}$ & $0,45 \pm 0,086 * * *$ & $0,50 \pm 0,083 * * *$ & $0,74 \pm 0,064 * * *$ & $0,74 \pm 0,065 * * *$ \\
\hline & глибина грудей & $0,84 \pm 0,052 * * *$ & $0,52 \pm 0,069 * * *$ & $0,64 \pm 0,074 * * *$ & $0,71 \pm 0,067 * * *$ & $0,78 \pm 0,060 * * *$ & $0,74 \pm 0,064 * * *$ \\
\hline & $\begin{array}{l}\text { обхват грудей за } \\
\text { лопатками }\end{array}$ & $0,75 \pm 0,064 * * *$ & $0,83 \pm 0,030 * * *$ & $0,91 \pm 0,039 * * *$ & $0,70 \pm 0,068 * * *$ & $0,81 \pm 0,057 * * *$ & $0,71 \pm 0,067 * * *$ \\
\hline & ширина таза & $0,74 \pm 0,064 * * *$ & $0,90 \pm 0,019 * * *$ & $0,96 \pm 0,028 * * *$ & $* 0,90 \pm 0,041 * * *$ & $0,92 \pm 0,038 * * *$ & $0,88 \pm 0,045^{* * *}$ \\
\hline \multicolumn{8}{|c|}{ Оброшинська біла породна група $(\mathrm{n}=128)$} \\
\hline \multirow{8}{*}{$\begin{array}{l}\text { Жива } \\
\text { маса }\end{array}$} & довжина тулуба & $0,92 \pm 0,034 * * *$ & $0,78 \pm 0,056 * * *$ & $0,73 \pm 0,061 * * *$ & $0,71 \pm 0,063 * * *$ & $0,73 \pm 0,061 * * *$ & $0,66 \pm 0,067 * * *$ \\
\hline & довжина кіля & $0,61 \pm 0,070 * * *$ & $0,81 \pm 0,052 * * *$ & $0,67 \pm 0,066^{* * *}$ & $0,64 \pm 0,068 * * *$ & $0,65 \pm 0,067 * * *$ & $0,80 \pm 0,053 * * *$ \\
\hline & довжина плесни & $0,49 \pm 0,077 * * *$ & $0,43 \pm 0,080 * * *$ & $0,63 \pm 0,069 * * *$ & $0,51 \pm 0,077 * * *$ & $0,69 \pm 0,064 * * *$ & $0,60 \pm 0,071 * * *$ \\
\hline & довжина гомілки & $0,31 \pm 0,085^{* * *}$ & $0,35 \pm 0,083 * * *$ & $0,71 \pm 0,062 * * *$ & $0,65 \pm 0,068 * * *$ & $0,66 \pm 0,067 * * *$ & $0,59 \pm 0,072 * * *$ \\
\hline & довжина стегна & $0,34 \pm 0,084 * * *$ & $0,39 \pm 0,082 * * *$ & $0,56 \pm 0,074 * * *$ & $0,67 \pm 0,066^{* * *}$ & $0,68 \pm 0,065^{* * *}$ & $0,68 \pm 0,066^{* * *}$ \\
\hline & глибина грудей & $0,79 \pm 0,054 * * *$ & $0,48 \pm 0,078 * * *$ & $0,60 \pm 0,071 * * *$ & $0,68 \pm 0,065 * * *$ & $0,70 \pm 0,063 * * *$ & $0,64 \pm 0,069 * * *$ \\
\hline & $\begin{array}{l}\text { обхват грудей за } \\
\text { лопатками }\end{array}$ & $0,79 \pm 0,055^{* * *}$ & $0,85 \pm 0,047 * * *$ & $0,85 \pm 0,046^{* * *}$ & $0,73 \pm 0,060 * * *$ & $0,68 \pm 0,065^{* * *}$ & $0,64 \pm 0,069 * * *$ \\
\hline & ширина таза & $0,60 \pm 0,071 * * *$ & $0,86 \pm 0,046^{* * *}$ & $0,90 \pm 0,039 * * *$ & $0,85 \pm 0,046^{* * *}$ & $0,79 \pm 0,054 * * *$ & $0,80 \pm 0,053 * * *$ \\
\hline
\end{tabular}

Це вказує на те, що добір гусей за живою масою можна проводити вже у 30-добовому віці.

При веденні селекційно-племінної роботи з птицею важливе значення має достовірність іiі оцінки за екстер'єром. На основі промірів тіла проводять оцінку росту й розвитку гусей, позаяк між ними і живою масою птиці існує певний зв'язок. Так, нами встановлено, що між живою масою і промірами тіла гусей 
оброшинської сірої та оброшинської білої породних груп у досліджуванні вікові періоди спостерігалися додатні, різної сили зв'язки (табл. 3,4$)$. Причому ці зв'язки у самців гусей обох породних груп були більш суттєвішими ніж у самок (виняток - обхват грудей за лопатками).

Найвищі коефіцієнти кореляції у птиці обох породних груп майже у всі досліджувані вікові періоди спостерігалися між живою масою та за шириною таза, довжиною тулуба, довжиною кіля і обхватом грудей за лопатками: у самок вони були в межах 0,58-0,96, а у самців - в межах 0,50-0,96 при $\mathrm{P}<0,001$ в усіх випадках. Проте варто зазначити, що зв'язки живої маси з довжиною тулуба та з довжиною кіля як у самок, так i у самців гусей оброшинської сірої породної групи були більш суттєвими ніж у їхніх ровесників оброшинської білої породної групи, тоді як зв'язки живої маси 3 шириною таза та обхватом грудей за лопатками, навпаки, були слабшими.

Щодо співвідносної мінливості живої маси та довжини стегна, гомілки й плесни, то, за винятком коефіцієнтів кореляції між живою масою та довжиною стегна, ці зв'язки були більш суттєвими у білих гусей. Залежно від віку птиці у сірих самок вони коливалися від 0,32 до 0,74, у самців - від 0,29 до 0,82, а у білих ровесників - від 31 до 0,71 та від 0,26 до 0,80 відповідно.

\section{Таблиця 4}

Зв'язок живої маси з промірами тіла самців гусей

\begin{tabular}{|c|c|c|c|c|c|c|c|}
\hline \multirow{3}{*}{\multicolumn{2}{|c|}{ Поєднання показників }} & \multicolumn{6}{|c|}{ Оброшинська сіра породна група $(\mathrm{n}=75)$} \\
\hline & & \multicolumn{6}{|c|}{ Віковий період } \\
\hline & & 30 діб & 60 діб & 90 діб & 120 діб & 150 & 180 \\
\hline \multirow{8}{*}{$\begin{array}{l}\text { Жива } \\
\text { маса }\end{array}$} & довжина тулуба & $0,88 \pm 0,025 * * *$ & $0,73 \pm 0,054 * * *$ & $0,81 \pm 0,039 * * *$ & $0,84 \pm 0,034 * * *$ & $0,80 \pm 0,042 * * *$ & $0,71 \pm 0,057 * * *$ \\
\hline & довжина кіля & $0,64 \pm 0,068 * * *$ & $0,81 \pm 0,041 * * *$ & $0,74 \pm 0,052 * * *$ & $0,88 \pm 0,027 * * *$ & $0,65 \pm 0,067 * * *$ & $0,73 \pm 0,056^{* * *}$ \\
\hline & довжина плесни & $0,43 \pm 0,094 * * *$ & $0,29 \pm 0,106^{* *}$ & $0,57 \pm 0,078 * * *$ & $0,60 \pm 0,074 * * *$ & $0,65 \pm 0,067 * * *$ & $0,59 \pm 0,075 * * *$ \\
\hline & довжина гомілки & $0,32 \pm 0,104 * * *$ & $0,48 \pm 0,089 * * *$ & $0,75 \pm 0,051 * * *$ & $0,77 \pm 0,046^{* * *}$ & $0,70 \pm 0,059 * * *$ & $0,45 \pm 0,092 * * *$ \\
\hline & довжина стегна & $0,57 \pm 0,077 * * *$ & $0,61 \pm 0,073 * * *$ & $0,70 \pm 0,059 * * *$ & $0,82 \pm 0,038 * * *$ & $0,73 \pm 0,054 * * *$ & $0,50 \pm 0,086^{* * *}$ \\
\hline & глибина грудей & $0,92 \pm 0,017 * * *$ & $0,55 \pm 0,080 * * *$ & $0,75 \pm 0,050 * * *$ & $0,79 \pm 0,043 * * *$ & $0,82 \pm 0,037 * * *$ & $0,89 \pm 0,025 * * *$ \\
\hline & $\begin{array}{l}\text { обхват грудей за } \\
\text { лопатками }\end{array}$ & $0,68 \pm 0,062 * * *$ & $0,78 \pm 0,046^{* * *}$ & $0,80 \pm 0,042 * * *$ & $0,88 \pm 0,026 * * *$ & $0,87 \pm 0,028 * * *$ & $0,72 \pm 0,056^{* * *}$ \\
\hline & ширина таза & $0,83 \pm 0,036^{* * *}$ & $0,84 \pm 0,034 * * *$ & $0,98 \pm 0,004 * * *$ & $0,86 \pm 0,025 * * *$ & $0,87 \pm 0,027 * * *$ & $0,78 \pm 0,046^{* * *}$ \\
\hline \multicolumn{8}{|c|}{ Оброшинська біла породна група (n=107) } \\
\hline \multirow{8}{*}{$\begin{array}{c}\text { Жива } \\
\text { маса }\end{array}$} & довжина тулуба & $0,96 \pm 0,026^{* * *}$ & $0,80 \pm 0,058 * * *$ & $0,95 \pm 0,031 * * *$ & $0,91 \pm 0,040 * * *$ & $0,89 \pm 0,044 * * *$ & $0,87 \pm 0,048 * * *$ \\
\hline & довжина кіля & $0,67 \pm 0,053 * * *$ & $0,89 \pm 0,045 * * *$ & $0,85 \pm 0,052 * * *$ & $0,70 \pm 0,070 * * *$ & $0,69 \pm 0,071 * * *$ & $0,88 \pm 0,047 * * *$ \\
\hline & довжина плесни & $0,50 \pm 0,084 * * *$ & $0,30 \pm 0,093 * *$ & $0,67 \pm 0,073 * * *$ & $0,62 \pm 0,077 * * *$ & $0,50 \pm 0,085^{* * *}$ & $0,55 \pm 0,082 * * *$ \\
\hline & довжина гомілки & $0,26 \pm 0,094 * *$ & $0,46 \pm 0,087 * * *$ & $0,79 \pm 0,060 * * *$ & $0,80 \pm 0,058 * * *$ & $0,73 \pm 0,67 * * *$ & $0,50 \pm 0,084 * * *$ \\
\hline & довжина стегна & $0,54 \pm 0,082 * * *$ & $0,43 \pm 0,088 * * *$ & $0,72 \pm 0,068 * * *$ & $0,71 \pm 0,069 * * *$ & $0,67 \pm 0,073 * * *$ & $0,45 \pm 0,087 * * *$ \\
\hline & глибина грудей & $0,82 \pm 0,056^{* * *}$ & $0,52 \pm 0,084 * * *$ & $0,70 \pm 0,069 * * *$ & $0,68 \pm 0,072 * * *$ & $0,82 \pm 0,055^{* * *}$ & $0,80 \pm 0,059 * * *$ \\
\hline & $\begin{array}{l}\text { обхват грудей за } \\
\text { лопатками }\end{array}$ & $0,70 \pm 0,069 * * *$ & $0,80 \pm 0,058 * * *$ & $0,78 \pm 0,062 * * *$ & $0,82 \pm 0,055 * * *$ & $0,80 \pm 0,059 * * *$ & $0,69 \pm 0,070 * * *$ \\
\hline & ширина таза & $0,72 \pm 0,067 * * *$ & $0,50 \pm 0,084 * * *$ & $0,93 \pm 0,036^{* * *}$ & $0,85 \pm 0,052 * * *$ & $0,82 \pm 0,056^{* * *}$ & $0,72 \pm 0,067 * * *$ \\
\hline
\end{tabular}

Варто зазначити, що в досліджуванні вікові періоди суттєві високовірогідні зв'язки спостерігалися також між живою масою гусей та глибиною їхніх грудей. У самок гусей оброшинської сірої породної групи ці зв'язки перебували в межах 0,52-0,84, у самців - в межах 0,55-0,92, а у птиці оброшинської білої породної групи - в межах 0,48-0,79, та 0,52-0,82 відповідно.

Варто звернути увагу, що найслабші зв'язки були виявленні між живою масою та довжиною плесни, гомілки і стегна у птиці обох статей обох породних груп у віковий період 30-60 діб. Однак у всі вікові періоди співвідносна мінливість живої маси та всіх досліджуваних промірів була високовірогідною.

\section{Висновки}

1. Встановлено, що маса молодняку гусей оброшинської сірої та оброшинської білої породних груп певним чином залежала від маси інкубаційного яйця. Найбільш суттєві і високодостовірні зв'язки були встановленні між масою інкубаційного яйця та живою масою гусенят у добовому віці. У подальші вікові періоди значення цих зв'язків різко знижувалися і у 60-добовому віці птиці сягали мінімальних величин та були невірогідними.

2. Добір гусей оброшинської селекції за живою масою доцільно проводити у 30-добовому віці, оскі- 
льки коефіцієнти повторюваності у птиці обох статей у цьому віці сягали понад 50\%.

3. Найвищі коефіцієнти кореляції у птиці обох породних груп майже у всі досліджувані вікові періоди спостерігалися між живою масою та шириною таза, довжиною тулуба, довжиною кіля і обхватом грудей за лопатками. Співвідносна мінливість живої маси та довжини тулуба й довжини кіля була вищою у сірих гусей, а живої маси та ширини таза й обхвату грудей за лопатками - у білих ровесників. Коефіцієнти кореляції між всіма досліджуваними ознаками у всі вікові періоди були високовірогідними.

Перспективи подальших досліджень. У подальшому буде вивчено успадковуваність господарськи корисних ознак гусей оброшинської сірої та оброшинської білої породних груп.

\section{References}

Fialovych, L., \& Kyryliv, I. (2016). The effective usage is in feeding of tribal geese of unconventional additions. Scientific Messenger of LNU of Veterinary Medicine and Biotechnologies. 18(2(67), 261-264. doi: $10.15421 /$ nvlvet6757.

Grishina, D.S. (2016). Vosproizvoditelnye i produktivnye kachestva pereyaslavskoy porody gusey: Dis. na soiskanie uchonoy. stepeni kand. s.-kh. nauk: spets (in Russian).

Khomyk, M.M. (2009). Husy obroshynskoi selektsii hospodarsko-korysni pokaznyky ta perspektyva vyroshchuvannia. Naukovyi visnyk LNAVM im. S.Z. Hzhytskoho. 11, 2(41), 234-239 (in Ukrainian).

Khvostyk, V.P. (2012). Intensyvnist rostu husei stvorenoi dymorfnoi populiatsii. Naukovyi visnyk LNUVMBT im. S.Z. Hzhytskoho. 14, 2(52), 348-350 (in Ukrainian).

Kyryliv, Ya.I., Perih, D.P., \& Paskevych, H.A. (2002). Konstytutsiia i eksterier s.-h. ptytsi: metodychni rekomendatsii. Lviv (in Ukrainian).

Lakin, G.F. (1990). Biometriya: uchebnoe posobie [dlya biol. spets. vuzov]. M.: Vysshaya shkola (in Russian).

Petriv, M., Sloboda, L., \& SlobodaO. (2017). Intensity of growth and development of the young of obroshyno gray geese generation crossed with big gray breed geese, $f$ ii generation, crossed with geese big seed of breed. Scientific Messenger of LNU of Veterinary Medicine and Biotechnologies. 19(74), 219-223. Retrieved from: https://nvlvet.com.ua/index.php/ journal/article/view/1136

Petriv, M.D., Sloboda, L.Ya., Zahorets, N.M., \& Sloboda, O.M. (2016). Pleminni ta produktyvni vlastyvosti obroshynskykh sirykh i bilykh husei za yikh rozvedennia. Visnyk ahrarnoi nauky. 1, 41-44 (in Ukrainian).

Pustova, N.V. (2004). Zviazok zhyvoi masy kurei z pokaznykamy produktyvnosti. Naukovo-tekhnichnyi biuleten Instytutu tvarynnytstva. 87, 112-115 (in Ukrainian).

Sobolev, A., Gutyj, B., Petryshak, O., Golodjuk, I., Petryshak, R., \& Naumyuk, O. (2017). Morphological and biochemical blood indicators of ducklings, which are raised for the purpose of meat with the different level of selenium in feeding-stuffs. Scientific Messenger of LNU of Veterinary Medicine and Biotechnologies. 19(74), 57-62. doi: 10.15421/nvlvet7413.

Sobolev, A., Gutyj, B., Grynevych, N., Bilkevych, V., \& Mashkin, Y. (2017). Enrichment of meat products with selenium by introducing mixed feeds for birds in their compound. Regulatory Mechanisms in Biosystems. 8(3), 417-422. doi: 10.15421/021764.

Zaplatinsky, V., \& Fedorovich, E. (2017). Morphological and biochemical blood indices of obroshinsky gray and obroshinsky white natural group geese ant its depending on their physiological state. Scientific Messenger of LNU of Veterinary Medicine and Biotechnologies. 19(79), 140-144. Retrieved from: https://nvlvet.com.ua/index.php/journal/article/view/1 275.

Zaplatynsky, V. (2017). The correlation between dimensional characteristics, live weight and fluff and feather level of obroshynska gray and obroshynska white natural groups geese. Scientific Messenger of LNU of Veterinary Medicine and Biotechnologies. 19(74), 156-160. doi: 10.15421/nvlvet7435. 